\title{
Design and construction of deep water quays at Dar es Salaam and Mombasa
}

\author{
L. C. PHILLIPS
}

\section{Mr Phillips}

Dar es Salaam, as well as being one of the ports for Zaire, also serves the two small states adjacent to the NW corner of Tanzania, Rwanda and Burundi.

60. When tenders were called for Dar es Salaam, tenderers were allowed to submit alternative designs or materials, but the Herkules jointed pile offered by the successful tenderer was the only alternative put to the Consulting Engineers. The joints were, in 1967 when the contract was let, a new concept. Nowadays they are well known and there are other similar types of joint. The idea of a jointed pile avoids the problems of handling long, heavy piles and allows flexibility in the length of piles without having to predetermine exactly the final required lengths of piles. At Dar es Salaam they were made $40 \mathrm{ft}$ long for the bottom and middle lengths and 10, 20,30 and $40 \mathrm{ft}$ long for the top lengths. The concrete strength recommended at the time by the supplier of the joints was $5600 \mathrm{lb} / \mathrm{sq}$. in. which proved adequate, although currently the recommended strength is $7200 \mathrm{lb} / \mathrm{sq}$. in.

61. In $\S 17$ reference is made to the tolerance built into the manufacture of the joints and to the flexure in the piles of as much as $1 \frac{1}{2}$ inches in $40 \mathrm{ft}$. This is 1 in 320 , and the Swedish code allows the two halves of the joints to be out of square by as much as 1 in 150. Fendering, bollards and ladders at Dar es Salaam were similar to those installed at Mombasa.

62. As at Dar es Salaam alternatives could be offered by tenderers for Mombasa. The only alternatives offered were caisson designs but neither of the two offers was cheaper than the conforming design by. Sir Lindsay Parkinson and Co. Ltd.

63. Corrosion is mentioned in $\$ 41$, and the tests carried out showed that below water level the rate of corrosion was about 0.007 in./year with about 0.015 in./year in the splash zone. In the original design of 1966 it was proposed to use Rendhex No. 4 piles, the thickness of which is $\frac{5}{8}$ in., and if one third of the thickness were allowed to corrode their life would be about 26 years. The Client required a life of 40 years and the thickness was to be increased by $\frac{1}{8} \mathrm{in}$. In the event Mannesmann tubes were used and the lower lengths were thickened by $5 \mathrm{~mm}$ and $5 \frac{1}{2} \mathrm{~mm}$ to give the required life.

64. The blasting of the hard shale of the harbour bed, normally 36 holes at a time, required on average $34 \mathrm{lb}$ of explosive per hole or slightly under $2 \mathrm{lb}$ of explosive per $\mathrm{m}^{3}$.

65. Berths 7, 8 and 9 at Dar es Salaam and the berths at Mombasa are designed to take container traffic. The Client also wanted wider quay aprons than had previously been the case at the two ports and at Dar es Salaam the raker piles incorporated to take fender blows and bollard pulls were used to take the seaward columns of the transit

Paper published: Proc. Instn Civ. Engrs, Part 1, 1977, 62, Nov., 563-583. 
shed and will take, if required in the future, the landward legs of the container cranes. At Mombasa, where the deck is narrower, additional rakers for this purpose are incorporated behind the deck.

\section{Mr J. de Greef, Ballast Nedam Groep NV}

Ballast Nedam participated for $50 \%$ of a joint venture with the Overseas Construction Company for the construction of the berths at Dar es Salaam. I would like to confine my contribution to those matters in which the Contractor had a hand, in particular the choice of piling. In this case there were three conditions which had to be considered: $(a)$ the pile had to be technically sound; $(b)$ it had to suit local ground conditions; $(c)$ the cost had to be less than that envisaged by the Engineer.

67. As to being technically sound, the Overseas Construction Company had experience of the behaviour of these piles. There was no particular risk in handling them. It was very clear from the beginning that the ground conditions would vary greatly, which of course, would pose a problem in respect of Rendhex piles, as the Contractor was responsible not only for the supply of the materials but also for any left over. In a country such as Tanzania, where there is no ready market for piles, it would cause quite a financial risk. The Paper comments that this is seen as a disadvantage of the Herkules pile. However, in making a comparison between the materials in the Herkules pile and the steel pile, the joints only amount to about $20 \%$ of the direct costs, whereas in the case of the steel piles they amount to about $65-70 \%$.

68. Fears as regards varying ground conditions were well founded. Based on experience of berths 4-8, the quantities for the contract on berths 9-11 seemed reasonable. A total of 5500 sections was envisaged to be cast, but in fact only 4200 were needed.

69. Another matter concerned the slope on the seaward side of the reclamation. The original design called for the incorporation of rubble banks along a slope of $1: 2$ with the intention that the Engineer could vary the slope in accordance with the ground conditions without increasing the amount of rubble in the banks. This is an expensive form of construction, and we tried to arrive at a slope of $1: 2$ directly, putting a rubble layer as protection on the top (the design described in the Paper).

70. This went well on the contract for berths $4-8$, but caused difficulties in the other contract, mainly due to the fact that the material used for the rubble bank was of a different nature. In the earlier contract the sand came from the harbour, was processed through a suction dredger and contained very few fines, whereas in the second contract for berths 9-11 the sand was mainly from the high ground with a large content of fines, and $1 \mathrm{~m}^{3}$ out of the bank gave only $0.72 \mathrm{~m}^{3}$ in reclamation. Nevertheless a fair amount of fines was retained which gave rise to slips and therefore delays.

71. As is indicated in the Paper, a well-point system was installed. On investigation the factor of safety against horizontal movement of the slope appeared safe at $1 \cdot 24$, whereas the factor of safety in respect of a circular slip was about 1 , which indicated a rather dangerous situation. The only thing to be done was to control the possibility of having the equilibrium disturbed, particularly by the piling plant which was working slightly behind and causing vibrations in the slope. The second possibility was to reduce the amount of fines in the material being reclaimed; finally a lowering of the phreatic line in the slope at low tides would improve the stability.

72. As regards the vibration from the piling plant, the distance between the unprotected slope and the piling was enlarged. To minimize the amount of fines the working of the suction dredger was limited to high tides, and a lowering of the phreatic line was effected by the installation of a well-point system along the edge of the slope.

\section{Mr J. D. Mettam, Bertlin and Partners}

While these works have been going on, I have been responsible for the preparation of master plans for the long term development of both ports. 

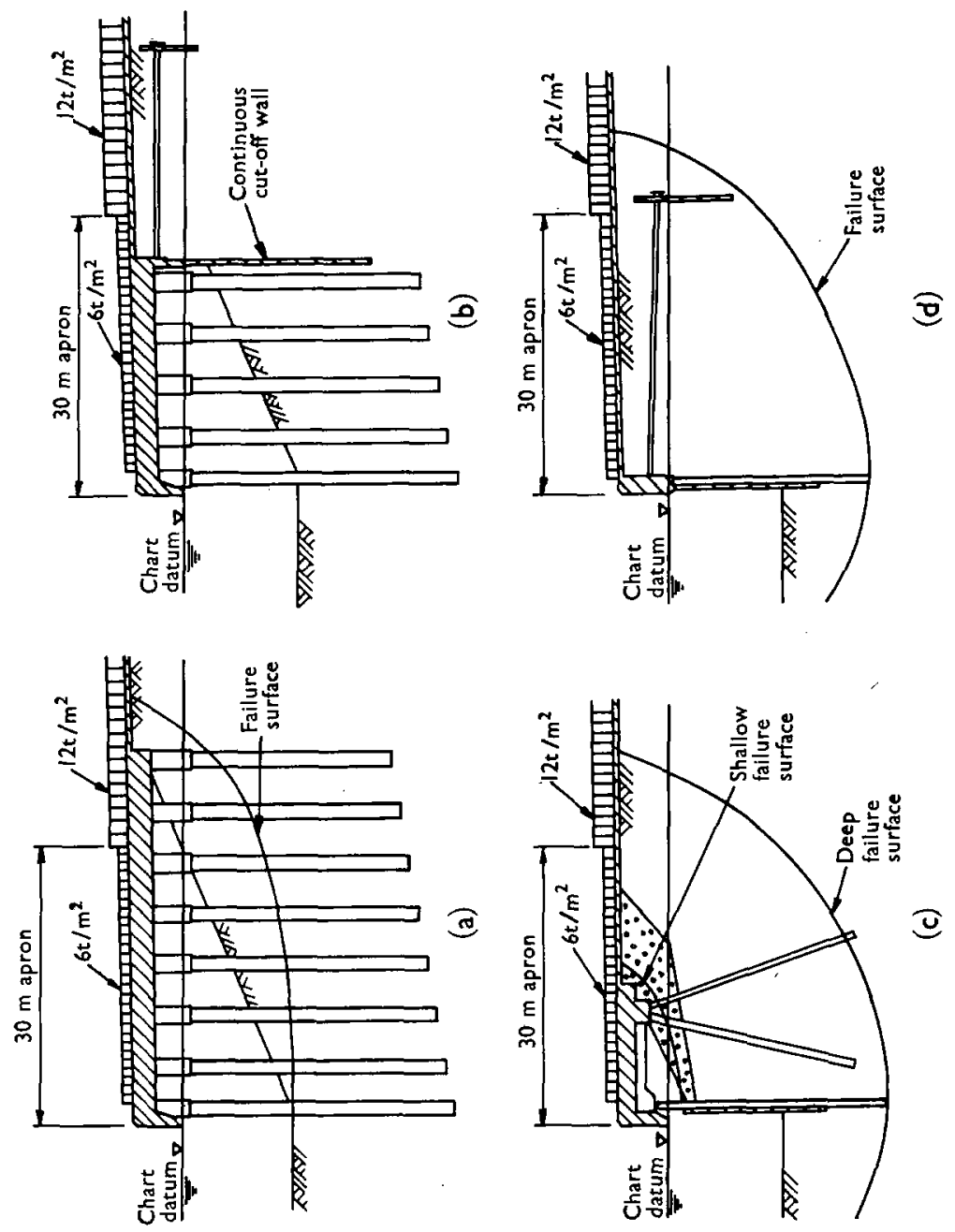
74. My comments relate to $\S 32$ where the Author refers to the complicated layout of rail tracks in Dar es Salaam, and the fact that this was simplified during the construction period. Bertlin and Partners started the United Nations development programme study of Dar es Salaam in 1973 when the first berths, 7 and 8, were under construction and berths $9-11$ were being planned.

75. Part of the problem was that there would have been two authorities operating trains running on the same land, but the worst problem was that the two railways were of different gauges. The East African Railway adopted the metric gauge at the beginning of this century, even though railways were coming south from Cairo and going north from Cape Town on a $3 \mathrm{ft} 6$ in. gauge. For some years people had talked of changing the EAR gauge to $3 \mathrm{ft} 6 \mathrm{in}$. but the cost would have been enormous. Tazara, linking up with Zambia, was on $3 \mathrm{ft} 6 \mathrm{in}$. and the difference between $3 \mathrm{ft} 6 \mathrm{in}$. and $1 \mathrm{~m}$ was $67 \mathrm{~mm}$ which made the two systems totally incompatible.

76. The study considered a complete range of possibilities from scrapping the track entirely to having as near as possible what the two railway corporations were then asking for. The difficulties of operating the two tracks would slow down cargo handling, particularly out of the sheds, to such an extent that as traffic grew the difference between having the rail tracks and not having them was worth about two berths. In the area before the creek becomes shallow it would be possible to build two more berths (12 and 13) and our traffic forecast showed that these would be necessary without the railways operation. However, if the rail operation continued, four extra berths would be required. These would have had to be built outside the harbour, so there was considerable cost disadvantage in having to build more berths. We found it would be much more economical not to handle rail traffic from the sheds or from the apron, but to build separate rail depots for Tazara general traffic, for the Zambian copper, and for the Zaire traffic.

77. We recommended that the shed planned for berths 9 and 10 should be moved up to 10 and 11 so that the three deepest berths could be built as a unit to handle container traffic. In principle these plans have been followed to a considerable extent. The copper depot terminal is under construction. Tazara depot is still being considered. The site investigations have been done for berths 12 and 13, and it is hoped that finance will be arranged for construction to start in 1979.

78. When we started a similar UNDP study of Mombasa, it became necessary to talk to East African Railways in Nairobi. The first thing they said to me before starting to give us information was that I must promise we would not eliminate all the railways in Mombasa as well as Dar es Salaam. I gave that promise and have kept it, but we have recommended a reduction there also, though not such a severe one.

\section{Mr J. G. Berry, Bertlin and Partners}

Loadings from the export of copper at Dar es Salaam are considerable. Loadings have been observed to range from $4 \mathrm{t} / \mathrm{m}^{2}$ for ingots to $12 \mathrm{t} / \mathrm{m}^{2}$ for baled sheet. The highest loadings are usually in areas behind the quay apron.

80. There may be occasions when, due to a hold-up in shipping, copper has to be stacked near the quay apron. In the project design for the proposed berths 12 and 13 recently completed for the Tanzania Harbours Authority, it was assumed that loadings of $6 \mathrm{t} / \mathrm{m}^{2}$ might in an emergency, be applied to the quay apron. Heavier loadings of up to $12 \mathrm{t} / \mathrm{m}^{2}$ were assumed possible for the areas behind the apron. These loadings influence the choice of type of quay structure. Fig. 11 shows the types of quay structure which were considered. Type (a), which is similar to that described by the Author, requires a very wide deck in order to avoid the risk of slip failure in the bank underneath. The potential failure plane is indicated.

81. One solution to this problem, shown in Fig. 11(b), is to provide a continuous rear cut-off wall to intercept the failure plane. However this involves the use of sheet piling which has to be tied back to resist permanent lateral earth pressures.

82. It is usually more economical to use a sheet pile wall as the main structural 


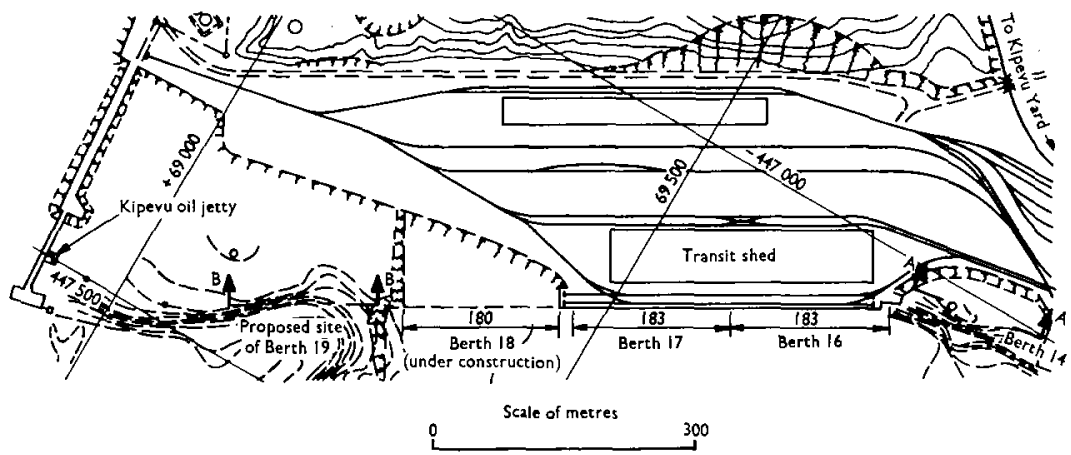

Fig. 12. Layout of berths: Mombasa

element. Fig. 11(c) shows a relieving platform type which has been used extensively in Holland. Cost comparison with the simple tied sheet pile design shown in Fig. 11(d) showed that in Dar es Salaam conditions the relieving platform scheme would not be the cheapest design.

\section{Mr W. R. V. Butcher, Bertlin and Partners}

I wish to confine my remarks to soil conditions on the Mombasa project. Bertlin and Partners are in a somewhat special position at Mombasa in that we are currently studying port developments on both sides of berths 16 and 17. One development is at berth 15 which was previously avoided because of the relatively poor soil conditions. The other is at berth 19 where conditions are similar to berth 15 (Fig. 12).

84. Figure 13 shows the geological formation at berth 15 . The bedrock is mudstone (in the Paper this is described as shale and use of the term 'mudstone' is only a marginal preference) with a highly weathered layer above it. The surface layer represents the lowest point of erosion of the original formation. At Mombasa, as at Dar es Salaam, there have been rises and falls in the sea level over a period of geological time which have caused successive erosion and infilling. The layer immediately overlying the weathered mudstone we have described as 'degraded mudstone'. This material is very similar in appearance to the highly weathered mudstone but the presence of foreign matter suggests that it has been transported and not weathered in situ. Because of this its properties can be expected to differ and it will probably be weaker.

85. There is more material described as 'degraded mudstone' at a higher level. This exhibits rounded fragments of mudstone, unlike the lower formation which has angular fragments. The former suggests water transportation and the latter movement due to slips. There is a similar pattern at berth 19 (Fig. 14) although only one layer of 'degraded mudstone' is present.

86. In the Paper the Author does not show the relationship of the quay structure to the soil strata on which it is founded. However, in $\$ 51$, he noted that a problem had been encountered with the rubble bank. It would be of interest to know on what stratum this bank has been founded, particularly in the light of soil conditions identified at adjacent berths.

87. The other question I have concerns the design of berths 16 and 17. The Author states that due to the high concentration of sulphate reducing bacteria in the soil it was decided to use steel instead of concrete piles, and to thicken the walls of the steel cylinders to allow for high corrosion. Our investigations for berths 15 and 19 revealed a sulphate 
concentration no higher than $0.42 \%$ which is not an alarming figure. For this sulphate level it would be normal to use a higher ordinary Portland cement content for concrete but it would not be necessary to use sulphate resisting cement. Would the Author comment on what tests the decision to use steel instead of concrete piles was based.

\section{Mr D. Kerr, Ove Arup and Partners}

When the port at Dar es Salaam was being designed I was working for Coode and Partners. When the East African Railways asked for a design for the extended berths at Dar es Salaam, Coode's produced to my knowledge at least seven designs, all of which were extensively costed in considerable detail. Several of these closely resembled those given in Fig. 11. The cheapest was in fact a circular cofferdam design. The design with concrete piles was not the cheapest by quite a large margin. The choice was dictated by the East African Railways and was not that preferred by the Consultants.

89. Amsterdam Ballast proposed their design because they had had extensive experience of that type of construction at Rotterdam. It was the cheapest simply because the Contractors understood exactly in every detail how to construct it. Instead of starting off with an untried team of men working with a design they had not seen before, their workmen were a long way along the learning curve and had built many kilometres of wall to that design.

90. A point was raised in connection with stacking copper on the quay wall, and the consequent heavy loading. The way copper was delivered to the quay caused a great deal of concern. I believe the port authorities are well aware of the risk of punching failure they would run if they overloaded the panels between the beams in the structure.

\section{Mr G. A. Metcalfe, Coode and Partners}

I was Resident Engineer at Dar es Salaam on berths 4-8. One of the lesser difficulties was the transit shed at berth 3 which had to be extended on to the rear of berth 4 , and the foundations at the south end of the transit shed had to be enlarged. When the shed was disconnected from the foundations, it shot up a few inches and the foundation dropped a few inches. It transpired that there was a large gap under the foundations and that the shed was holding up the footings.

92. Reference has been made to slips in the slope of the pilot bank. The pilot bank was essentially the Contractor's design and completely different from the contract design. The Contractor wanted to fill the pilot bank to the correct base line only, which obviously left a loose, lightly filled layer on the surface. This unstable layer tended to slip, particularly when there was a certain amount of silt accumulation on the face. This was largely overcome by overfilling and cutting back. Much of the fill excavated from behind the wharves was placed as underwater filling. In its original state it was not suitable because it had $30 \%$ clay, but by placing the fines hydraulically the clay fraction was washed away, leaving the coarse fraction behind. Apparently the Contractor did not like this on berths $9-11$, but on berths 7-8 the system seemed to work well and produced an estimated saving of 4 million shillings.

93. The biggest problem was probably the piling. From the beginning broken piling bedevilled us. The specification was simple. The pile was to be driven to $30 \mathrm{ft}$ penetration and had to carry about 200 tons. Since all piles on a job cannot be tested, some piles were driven to the set corresponding to a Hiley resistance of 200 tons, tested and found satisfactory, and a decision was taken to work to that set. Very soon the Contractor complained that driving to that set was breaking the pile. The real cause of the breakages was never truly established but may have been because the piles were being driven from a floating rig. As the piles were released at the end of driving it was noticed that the head sprang quite vicously. Obviously the piles were under some form of stress from being held in the helmet and the floating rig was not following the raking piles as they were driven while the sea level was altering. The piles near the 

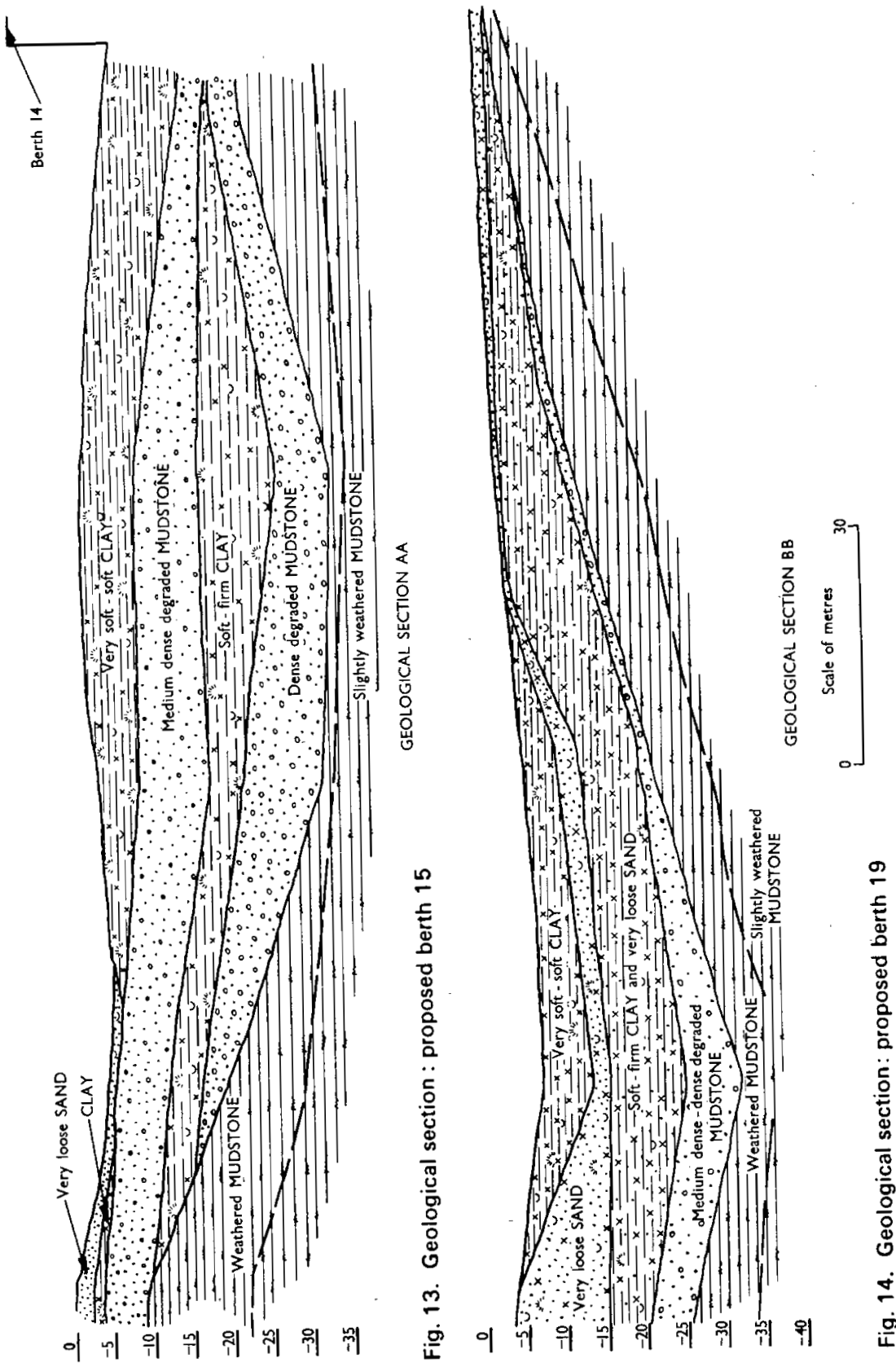
front wall were also rather long and with a floating rig it is almost impossible to use a gate lower than water level to hold the piles. On berths 7 and 8 for the extra work ordered the piles were driven from a land based gantry and after that came into operation the failures were certainly much fewer.

94. A third reason adduced by the Contractor for failures was that the piles were being over-driven, and he suggested that they should be driven to a lesser set, though he declined to indicate what this should be. Eventually the piles were driven to about $80 \%$ of the Hiley set, tested and found satisfactory. In successive stages they were driven to $65 \%, 60 \%$ and $50 \%$ of the Hiley set, and with each reduction there were fewer damaged piles, though still some cracked or broken.

95. At this stage the Contractor suggested that the hammer drop could be reduced. The hammer drop being used was $3 \mathrm{ft} 6 \mathrm{in}$. which for a 10 ton hammer is fairly normal. The Contractor suggested reducing this to $2 \mathrm{ft}$ or $1 \mathrm{ft} 6 \mathrm{in}$. It was very difficult to correlate a $3 \mathrm{ft} 6 \mathrm{in}$. drop and a $2 \mathrm{ft}$ drop with a 10 ton hammer. It is possible to drive the pile to the correct set with a $3 \mathrm{ft} 6 \mathrm{in}$. drop, and change to a $2 \mathrm{ft}$ drop with no connection between the two sets of results. The modulus of elasticity of the pile was tested and the stress analysis used to assess the stresses in the top end. The modified temporary compression was then applied into the Hiley formula. This gave a reasonable result and the pile tested satisfactorily. All these reductions resulted in a set being reached at 43 blows/ft instead of 400 blows/ft. This may lend some weight to the Contractor's argument that the piles were being overdriven, but perhaps the Contractor should have been more aware that it is up to him to provide proposals on how he intends to achieve what the consulting engineer requires by his specification.

96. When we test-loaded the piles to 200 tons they did not fail, but we had no idea what the margin of safety was. Perhaps there is scope for the development of specifications to allow for perhaps $20 \%$ overload if the pile has not failed at the proof load. At least there should then be some idea of how much safety margin there is.

\section{Mr J. E. Abura, Bertlin and Partners}

I was Chief Engineer of the East African Harbours Corporation (EAHC) at the time these works were being undertaken. The Author and $\mathrm{Mr}$ Mettam have both made reference to the gauges of rail tracks in the port of Dar es Salaam.

98. Difficulties arose not only because of these gauge differences but also because the two railway organizations, East African Railways Corporation (EARC) and Tanzania Zambia Railways Authority (Tazara) both wanted maximum facilities within the port operational areas. The government became concerned and several meetings were held to try to reach agreement, one of which was attended by the Author.

99. In addition, though Tazara management was consulting with EAHC on operation and policy matters in the port area, technical matters were being dealt with by the Chinese 'working team'. It was necessary to explain the EAHC plan to the working team well in advance to avoid delays in the contract work. Delays were sometimes unavoidable; but once identity of views was reached progress was rapid. In particular, the Chinese working team undertook to lay the length of track within the area covered by the contract, joining to a prelaid length forming the turn-out on the southern end of berth 11 .

100. In Mombasa where only one railway system is in operation, this particular problem did not occur. However, in both cases, our task in EAHC was the same with our relationship with the governments in Kenya and Tanzania, who were represented by their directors on the Board of the East African Harbours Corporation.

101. The difference in unit cost of berth construction which is evident from the Paper may be explained partly by increase in costs which occurred following the oil crisis in 1973. The construction of the two berths in Mombasa was well advanced, whereas at Dar es Salaam, a major contract involving the construction of three berths had only just started. The works had a tight schedule to be completed before the commissioning of Tazara Railways. In the event, this was largely accomplished. 
Mr J. W. Hunter, formerly Coode and Partners

I have earlier experience of Dar es Salaam and Mombasa, having worked there with Coodes in 1928 and 1929.

103. The Paper records an incident of piles moving in the bank at Mombasa. This recalled a similar but smaller job I was on at Portsmouth. During driving here, the piles moved in the head and on occasions broke. This was overcome by fairly simple methods, but when the job was finished movements were recorded which fitted a slip circle. The movements were circular about two centres, one in a vertical plane and the other in a horizontal plane. It turned out not to be slip circle trouble, but was caused by consolidation of the ground below the dredged level of the berth. The weight of the material in the reclamation was pulling the whole structure down vertically and there was slight horizontal rotation as well. The main problem was due to consolidation of the ground dragging the piles down and pushing them into the harder material below.

104. In the adjoining berth, which was slightly different, the piles were lengthened and there was no similar trouble, although the conditions were the same as regards consolidation of the ground. Was the slip at Mombasa in soft material, or was it consolidation of material that caused the slip?

105. In both ports the Paul Vahle system is used for picking up current for the cranes. I have always used a trailing cable and found it satisfactory. I have seen trouble with the Paul Vahle system and I wonder why it was used and what is its attraction.

106. Roughly $0.3 \%$ copper was put in the steel piles at Mombasa. Were there special features to make it advisable there, when considerable doubt has been expressed as to its effectiveness against corrosion?

The Chairman, Mr P. A. Cox

The driving rig at Mombasa travelled on a substantial temporary works attached to the piles: was there any serious damage to the pile coating or any problems in repairing this?

108. Both designs show a form of deck with a flat soffit which is obviously very good for maintenance. This also has a number of advantages for laying in track and putting in pipes and other services. It is, nevertheless, a somewhat unusual design. It would be interesting if the Author could comment on alternative designs for the deck.

109. Commenting on Mr Metcalfe's remarks on the Hiley formula, I should like to ask whether the pile joints could have some effect on the use of this formula. Presumably although there are grub screws holding the two sections together, the joints do not transmit tensile force. This might affect the propagation of stress in the pile and perhaps make the Hiley formula not necessarily valid in the form in which it is normally used.

Mr P. F. B. Tatham, Livesey and Henderson

Herkules joints have been used for over 20 years for piling on land but there are few papers on their use in marine works. It is therefore valuable to have the description in $\$ \$ 15-24$. How were the concrete collars $(\$ 18)$ placed?

111. It is not clear why sets based on the Hiley formula $(\$ 24)$ should lead to extremely hard driving. The driving resistance of $200 \mathrm{t}$ on a $0.2 \mathrm{~m}^{2}$ pile gives a stress on the gross cross section of $10 \mathrm{~N} / \mathrm{mm}^{2}$. Contractors using Herkules joints in the UK go as high as $15 \mathrm{~N} / \mathrm{mm}^{2}$ for working load on a fully embedded pile.

112. What were the wave conditions at Dar es Salaam necessitating rubble facing $3 \mathrm{ft}$ thick of $5 \mathrm{cwt}-28 \mathrm{lb}$ stones, on top of a $6 \mathrm{ft}$ thick layer of stones of $1 \frac{1}{2} \mathrm{cwt}$ maximum size, all at a slope of $2 \frac{1}{8}: 1$ (Fig. 4). In $\S 1$ it is stated that the harbour is totally enclosed and in $\$ 13$ that the pitching stone is expensive.

113. Can the problem of pile movement, mentioned in $\S \S 51$ and 52 , be more fully described, with a diagram showing the nature, cause and magnitude of the movements? Full descriptions of such problems are always valuable. 


\section{Mr E. L. Barron. Peter Fraenkel and Partners}

Since both contracts were financed by the World Bank, presumably the contracts were based upon the FIDIC Conditions, but since the Dar es Salaam contract was negotiated, was a target price contract used or even considered? Since the contract period was 27 months for Dar es Salaam and 39 months for Mombasa, one would expect the contracts to have included provision for price fluctuation. Could the Author outline the price fluctuation arrangements and any other contract arrangements that proved either particularly useful or onerous.

115. In $\S 42$ the Author says that tubes were primed with zinc primer at the manufacturer's works and painted at site. This was suprising because the DoE anticipate only 4 weeks protective life for zinc-rich primers under exposed conditions, and one would expect much more than 4 weeks to have elapsed between the priming at manufacturer's works and the site painting in this case. Was the zinc primer specially formulated to give extended weathering properties? According to Nicklin, ${ }^{4}$ when signs of rust appear on the face of a primer it can be assumed that almost the entire substrate has some measuring of rust on it, and the only correct treatment is complete reblasting to remove the primer. Did any such reblasting prove necessary?

116. Finally, could the Author give details of the standard specified for the site welding of tubes and associated non-destructive testing, together with the welding and weld repair procedures used. On pipeline, the economy of automatic welding is offset by the need for manual repair of defects, and for piles there is also the need for manual welding should extension of driven tubes be necessary.

\section{Mr Phillips}

Mr Butcher asks for information regarding the stratum on which the rubble retaining bank at Mombasa is built. In berth 16 and the east and west ends of berth 17 the bank is founded on hard shale. For the remaining part of berth 17 the bank is founded on the sand deposited as shown in Fig. 9. It appears, however, from subsequent investigations that a layer of clay of varying quality was left under the bank or was the result of deterioration of the shale which had been exposed during dredging. This material has probably allowed for settlement into it of the rubble and reclamation filling and although slip circle analyses have been carried out, in answer to Mr Hunter, it is not thought that such failure is the principal reason for movement in the piles.

118. As far as the Author is aware, no quantified assessment of the sulphate concentration was made for Mombasa, but comparative costs were made by corrosion specialists, based on their investigations of the site conditions, which showed that having regard to very real doubts that cathodic protection would be properly maintained, additional thickness in the steel piles was the most economical way to couriteract the probable corrosion.

119. Mr Kerr referred to the number of different designs that were investigated for Dar es Salaam. Although not the cheapest, the piled design took into account slip circle analyses, and having regard to the variable nature of the ground, a rubble retaining bank such as that at Mombasa would have proved unstable. The slope of the face had to be no greater than 1 in $2 \frac{1}{8}$ for an acceptable factor of safety, and to achieve this a series of small trapezoidal rubble banks, with filter and heavier facing stones, was incorporated in the design at tender stage. After the contract was let the Contractor put forward the design, accepted by the Consulting Engineers, for a protective facing to the filling, which protection was largely put down before piling to prevent slips in the face of the sand fill. The quantity of protection allowed the Contractor to recoup his overhead costs by providing the same amount of stone at the schedule rates in the contract.

120. Whilst the stone was expensive the quantity used was no more than that included in the tender design, and even if the maximum stone size ( $5 \mathrm{cwt}$ ) may appear large in an enclosed harbour where the wave heights are small, the percentage of such stone was small.

121. Mr Hunter referred to the Paul Vahle system for picking up the current for the 
cranes. When berths 1, 2 and 3 were built in the 1950s the current was supplied through trailing cables from plug boxes set at $50 \mathrm{ft}$ centres, alternate boxes being connected to one of two circuits. The change to Paul Vahle gear was made by the Client and incorporated by them in the subsequent berths.

122. The answer to his question on the use of copper in the steel of the piles at Mombasa is that this was advised by the corrosion specialists referred to in $\S 118$.

123. The rig for pile driving travelled on joints which were fixed to temporary caps on the piles, and so damage to the piles was not caused thereby.

124. Mr Cox also enquired if any alternative designs were considered for the decks. This was not done, as the requirements of the Client for the various services and the loading from the rail tracks led naturally to the design adopted. Although it meant additional loading from the stone filling the many advantages, including the spreading of point loads over a large area of deck slab, easily outweighed the disadvantages.

125. The grub screws mentioned in $\S 15$ did not hold the two halves of the He $\cdot k_{1}:$ les joints together, but only prevented them from becoming unlocked.

126. The Author is also inclined to agree with Mr Cox that the Hiley formula may not be necessarily valid for articulated piles. In $\S 111 \mathrm{Mr}$ Tatham refers to the harc driving when sets were based on the Hiley formula. This was due to the hard ground into which the piles in the early parts of the berths were driven when the driving resistance greatly exceeded the required loading of 200 tons. A driving formula becomes ineffective if the toes of the piles penetrate unyielding ground.

127. The movements of the piles referred to in $\$ \$ 51$ and 52 were subject to a number of influences, principally in the way the rubble of the bank was placed. When this was done by end tipping the movement was much greater than when placed by grab, and the movements were, in general, apparently related to the depth of rubble in which the piles were buried. All piles were driven into hard shale and there is no question of any movement of the toes of the piles. The maximum movement of a pile head was about $1.3 \mathrm{~m}$ in a landward raker, but the other piles in the same bent had progressively less movement as the amount of rubble surrounding them was less, the seaward pile moving as little as $5 \mathrm{~cm}$.

128. In answer to Mr Barron's first question, the contract conditions were not FIDIC but those drawn up and used by the Consulting Engineers over many years. They were, of course, approved by the World Bank.

129. The price fluctuation arrangements were simple, in that the Contractor was required to submit a list of basic prices of permanent materials on which his schedule rates were based, substantiated with copies of the relevant suppliers' quotations. Basic labour rates were those gazetted by the governments and applicable at the time of tender. The Contractor was reimbursed the differences in cost between the actual cost paid for materials and the basic costs and, with regard to labour, any increases over the basic costs of new rates promulgated by the governments. Temporary materials and plant were not allowed for price fluctuation, although increases in freight on permanent materials were allowed.

130. The zinc primer used for the Mombasa piles was epoxy based. No trouble was experienced with it or caused by it not being overcoated for up to 6 months after application. No site reblasting was necessary. Welding of the tubes was specified to to be BS 938:1962: no site testing of welds was carried out, nor were any failures of joints reported.

\section{Reference}

4. Nicklin R. J. P. Prefabrication primers and their misuse. Struct. Engr, 1973, 51, Oct., A15-16.

\section{Corrigenda}

In Fig. 2: North is to the right. Table 7: an asterisk should appear against item 4, column 2. 